\title{
O processo criativo de um livro ilustrado: uma experiência em artes visuais
}

The creative process of a picture book: an experience in visual arts

El proceso creativo de un libro

ilustrado: una experiencia en artes visuales

Maria Clara de Oliveira Pacheco ${ }^{1}$ Arlete dos Santos Petry ${ }^{2}$

${ }^{1}$ Artista visual e ilustradora, graduada no Curso de Licenciatura em Artes Visuais pela UFRN e graduanda do Curso de Pedagogia pela mesma universidade. lattes.cnpq. br/8110040254652978 | orcid.org/0000-0002-4444-2041 | quilarap@gmail.com.

2 Professora do Departamento de Artes da UFRN na área de Arte/Educação e professora do ProfArtes e do Programa de Pós-Graduação em Inovação em Tecnologias Educacionais, ambos da UFRN. lattes.cnpq.br/7426037066308934 | orcid.org/00000003-3120-8501 | arletepetry@gmail.com. 


\title{
Resumo
}

Livros ilustrados são produções culturais que associam, em um mesmo suporte, a linguagem visual e a linguagem escrita. A ilustração pretende sugerir novas leituras e interpretações a partir daquilo que o leitor está vendo, instigando a imaginação. Visando entender essa relação entre texto e imagem, é apresentado um recorte sobre o que deve fazer uma ilustração, qual o seu papel no livro ilustrado e o que é necessário a ela. A literatura destinada ao público infantil é outro ponto abordado nesta pesquisa em arte, bem como a organização da disposição dos elementos no processo de diagramação. O foco do trabalho está no processo de criação do livro ilustrado A Galinha Branca, levando em consideração como ele foi pensado, executado e registrado. Sendo assim, o estudo teórico acerca dos tópicos abordados vem como resposta às experiências práticas vivenciadas, dissolvendo as fronteiras desses dois aspectos da pesquisa.

\section{Palavras-chave}

ilustração; livros ilustrados; literatura infantil; processo criativo.

\begin{abstract}
Picture books are cultural productions that mix visual and oral language in the same structure. The illustration is intended to suggest new readings and interpretations from what the reader is seeing, instigating the imagination. In order to understand this relationship between text and image, a clipping is presented about what an illustration should do, what its role in the picture book is and what is needed to it. Children's literature is another point addressed in this research in art, as well as the organization and the arrangement of elements in the layout designing process. This work's focus is on the creative process of the picture book The White Chicken, considering how it was thought, executed, and recorded. Thus, the theoretical study about the covered topics comes in response to the practical experiences, dissolving the boundaries of these two aspects of the research.
\end{abstract}

\section{Keywords}

illustration; picture book; children's literature; creative process.

\section{Resumen}

Los libros ilustrados son producciones culturales que combinan lenguaje visual y lenguaje escrito en el mismo medio. La ilustración intenta sugerir nuevas lecturas e interpretaciones basadas en lo que el lector está viendo, instigando la imaginación. Para comprender esta relación entre texto e imagen, se presenta una sección sobre lo que debe hacer una ilustración, cuál es su papel en el libro ilustrado y qué es necesario para ella. La literatura para niños es otro punto abordado en esta investigación en arte, así como la organización de la disposición de los elementos en el proceso de diagramación. El enfoque del trabajo está en el proceso de creación del libro ilustrado La Gallina Blanca, teniendo en cuenta cómo se pensó, ejecutó y grabó. Por lo tanto, el estudio teórico sobre los temas mencionados responde a las experiencias prácticas vividas, disolviendo los límites de estos dos aspectos de la investigación.

\section{Palabras-clave}

ilustración; libros ilustrados; literatura infantil; proceso creativo. 
Este artigo trata a respeito do processo criativo do livro ilustrado1, A Galinha Branca, partindo de princípios relativos às etapas de criação da ilustração, a relação da imagem pictórica e do texto literário, além de conceitos específicos da literatura ilustrada e da literatura infantil, e de processos criativos.

O livro é uma produção autoral, voltada ao público infantil (de seis a oito anos), na qual foi proposto equilibrar a escrita e a criação de imagens, de modo que uma linguagem não fosse superior à outra, sucedendo em uma relação de equidade e soma de valores. Como explica Fittipaldi (2008), a imagem narrativa não busca se sobressair ao texto, mas visa juntar-se a ele e amplificar as perspectivas de leitura.

Meireles (2016) reflete acerca da preferência das crianças por algumas histórias e outras não. Segundo ela, a literatura infantil seria aquela que as crianças leem com agrado. Dessa forma, o questionamento principal proposto é: o que é necessário para a criação de um livro ilustrado? O que seria essencial em um livro ilustrado para despertar na criança o interesse?

Meireles diz que, graças a nomes como Perrault e Grimm, narrativas clássicas de outrora foram transcritas, perdurando até hoje. Nesse viés, o livro ilustrado foi um modo de guardar histórias familiares para além da oralidade, a fim de não se perderem no tempo. Além do valor sentimental significativo, essa pesquisa justificase pela necessidade de discutir o lugar da ilustração, e, abrangendo temas tocantes aos tópicos citados, age como base para estudos similares.

Este artigo foi organizado em quatro seções. A primeira traz uma discussão acerca da narrativa e da sua construção, apresentando relatos e os resultados obtidos na pesquisa teórica realizada neste âmbito, com a intenção de responder ao questionamento que indaga o que é necessário para escrever histórias infantis.

Seguindo adiante, a segunda seção trata das ilustrações, contando com relatos de suas produções, expondo a repercussão dos estudos realizados dentro desse recorte e procurando responder o que é necessário a uma ilustração. A terceira seção trata da relação estabelecida entre texto literário e imagem pictórica no livro ilustrado, refletindo sobre de que modo uma ilustração produzida para o livro se relaciona com a narrativa dele. Aborda-se também a necessidade de realizar uma diagramação consciente, apresentando relatos breves acerca de como se deu o processo de diagramar A Galinha Branca. Por último, apresenta-se uma seção que discorre a respeito do processo criativo em si e de como tudo foi registrado. Esse tópico também trata a respeito desse registro, como foi feito e como foi pensado.

Esta pesquisa baseou-se na abordagem de pesquisa em arte, que, de acordo com Zamboni (2012), refere-se a trabalhos relacionados à criação artística, realizados objetivando ter como produto a obra de arte. A abordagem viabiliza uma reflexão sobre o ato de criar, facilitando e orientando o artista pesquisador, de forma que promova a interação de componentes da pesquisa, como a observação, a reflexão e

\footnotetext{
${ }^{1}$ Importante destacar aqui que, o conceito de livro ilustrado utilizado nesse trabalho condiz com a definição do objeto dada por Van der Linden (2011, p. 24): "obras em que a imagem é preponderante em relação ao texto, que aliás pode estar ausente. A narrativa se faz articulada entre texto e imagem".
} 
a experiência. Posto isso, foi proposto que o processo estivesse evidente na estrutura do trabalho. Assim, os tópicos foram apresentados na ordem cronológica em que foram ocorrendo, e os conteúdos foram organizados e expostos da forma como foram surgindo no caminho e se agregando à pesquisa.

Para atender essa proposta de processo revelado, foram utilizados os fundamentos da A/r/tografia. De acordo com Dias (2013), essa forma de pesquisa baseada em arte, eleva o papel da criatividade, de modo que o saber, fazer e realizar se fundem, buscando meios alternativos para motivar entendimentos e saberes que os formatos tradicionais da pesquisa não são capazes de fornecer.

Para discussão acerca do processo criativo, a autora utilizada foi Salles (2006 e 2013). Adotou-se a expressão "ações de pesquisa" para designar as etapas do processo sem que estas tenham obrigação de uma ordem de acontecimento distinta. O trabalho foi dividido em cinco ações: consulta bibliográfica; construção da narrativa; concepção das ilustrações; relação texto $\mathrm{x}$ imagem; registro do processo criativo. Vale salientar que todos os passos foram registrados em um caderno de artista, que também se tornou uma das fontes de estudo desse processo criativo.

\section{Construção da narrativa}

A ideia inicial era fazer o enredo do livro ser construído em torno de histórias acerca da meninice de várias pessoas, porém, ao mesmo tempo que a diversidade na fonte das histórias seria um fator interessante, seria igualmente um problema, posto que seria necessário contextualizar e situar o leitor para cada nova narrativa.

As primeiras histórias foram coletadas partindo de experiências da infância da mãe e das tias de uma das autoras, no contexto de meados da década de 70 em uma casa simples no interior do Rio Grande do Norte. Cresceram dez irmãos juntos, correndo pelos quintais e roçados, fazendo suas sapequices, fato que lhes rendeu uma quantidade considerável de histórias. Ao mergulhar nesse universo, foi possível perceber que já tinha material suficiente para produzir o livro.

Com os relatos em mãos, registrados em gravações, passou-se a reescrevê-los, fazendo alterações que foram julgadas necessárias para se adaptarem ao formato da narrativa do livro. Decidiu-se por organizá-los em pequenos contos, uma vez que seriam muitos acontecimentos para uma única leitura. Então, cada um dos enredos vividos pelas crianças seria um conto. Ao total, foram escritos treze contos.

Considerando custos de produção e tempo, optou-se por focar em apenas um dos contos. O conto escolhido para o primeiro livro foi A Galinha Branca, que conta a história de uma das crianças e da sua galinha de penas alvas, que não podia andar pelo quintal sem ficar suja de lama. Assim, os demais contos ficaram como proposta de produções futuras, continuando a Coleção Histórias da Casa das Dez Crianças.

Ao escrever os contos, discutia-se como escrever histórias para crianças. O que é necessário a esses textos? Primeiramente, é preciso destacar que, apesar de o 
conceito de literatura infantil ${ }^{2}$ ser, basicamente, a produção de textos voltados para crianças, o que se julga próprio à literatura infantil nem sempre é o que vai interessar aos leitores desse grupo. Ou seja, como diz Meireles (2016), quem deve dizer se os livros são ou não apropriados, úteis ou prazerosos para crianças são elas mesmas.

Meireles também diz que não é possível seguir uma "receita de bolo" para a criação dos livros infantis. Isto é, não se pode determiná-los definitivamente, uma vez que não existe um tema específico para crianças, nem mesmo um gênero literário destinado a elas. Para mais, não basta simplificar textos que seriam para o público adulto para que estes possam ser classificados como infantis.

Cademartori (2006) explica que, quando se delimita a quem aquele tipo de literatura se destina, pressupõe-se que é possível saber o que vai interessar ao público em questão. Portanto, seus elementos, linguagem, pontos de vista e temas estariam moldados de acordo com a interpretação do autor. Essa pretensão pode ser problemática, por causa da relação de dependência que a criança tem para com o adulto, agravada pela ausência de correspondência entre autor e leitor. Com isso, a literatura infantil finda tomando o formato de uma linguagem e de um estilo que o adulto acredita serem apropriados para o jovem leitor, aproveitando para transmitir valores que são considerados essenciais para a formação infantil.

Durante a construção da narrativa, hesitou-se quanto a contar para crianças histórias sobre outras crianças que não eram bem-comportadas, pela questão de como impactaria os leitores. Entretanto, como foi dito, o objetivo aqui não é filtrar o que se acha, como adulto, que seria do interesse de uma criança para leitura, uma vez que esse papel apenas a própria criança poderia realizar.

Brenman (2012) diz que a cultura criou produções de arte diversificadas para fortalecer a alma da criança, e que isso faz parte de seu desenvolvimento saudável. Crianças aprontam e aprendem com isso, e, ao poder se identificar com personagens que fazem o mesmo, é possível conseguir maior interesse por parte delas. Ele sugere que os adultos se lembrem de quando eram crianças e do que gostavam ou não. $\bigcirc$ propósito deve ser produzir livros que façam as crianças mergulharem no universo que está naquelas páginas, que seus textos e significados fiquem cristalizados nelas, bem como suas ilustrações.

Entendendo que a intenção é tratar de assuntos que interessam à infância, como saber se um livro como A Galinha Branca estaria apto a ser apreciado por um público composto por crianças? Responde-se essa pergunta retomando Meireles (2016): é necessário submeter o livro ao uso da criança e ver como ela interage com ele. Para tanto, foi realizado uma apreciação com as crianças da Escola Estadual Hegésippo Reis, onde alunos na faixa etária correspondente ao público alvo do livro tiveram acesso à história de Tuca e de sua Galinha de penas brancas.

Nesse momento, foi conversado com eles sobre como acontecem coisas na nossa vida que poderiam ser histórias interessantes ou engraçadas, citando exemplos

\footnotetext{
2O termo "infantil" é empregado no sentido daquilo que diz respeito ou é relacionado à criança, não como algo imaturo ou pueril.
} 
pessoais das autoras para ajudar no entendimento. Em seguida, foi pedido que eles pensassem em uma situação cômica vivenciada por eles ou por conhecidos. Então, fizemos a leitura do texto e das imagens presentes em A Galinha Branca. A recepção foi muito positiva, possibilitando ver que o livro conseguira prender a atenção das crianças e causar encantamento. Por fim, relacionamos o tema inicial discutido com a história por trás da narrativa, e foi realizada uma oficina de construção de imagens narrativas, partindo dos relatos deles.

\section{Concepção das ilustrações}

Os personagens do livro A Galinha Branca foram referenciados em pessoas ou animais reais, que conviveram no contexto familiar citado acima. Assim como as histórias que compõem o enredo, os personagens já existiam, cabendo a nós apenas o papel de desenvolvê-los. Para a concepção deles, foram traçados perfis tendo em conta a idade, o caráter das pessoas que os inspiraram e os acontecimentos contidos nos relatos. Essa etapa foi importante para que, durante o desenvolvimento da narrativa, eles se mantivessem constantes. Quanto à parte visual, buscou-se imagens de pessoas nas faixas etárias específicas, além de fotos do acervo familiar, e em seguida foram feitos desenhos imaginando como seriam fisicamente, procurando atribuir algo da personalidade desenvolvida para elas.

Para a construção das cenas, foram pesquisadas imagens que possibilitaram estudar anatomia, posições e expressões que seriam representadas. Partindo daí, foram feitos esboços de possibilidades, até chegar àquelas que comporiam as ilustrações definitivas. Considerando que, para os animais também foram atribuídas personalidades e expressões, a pesquisa de imagens também se estendeu a eles.
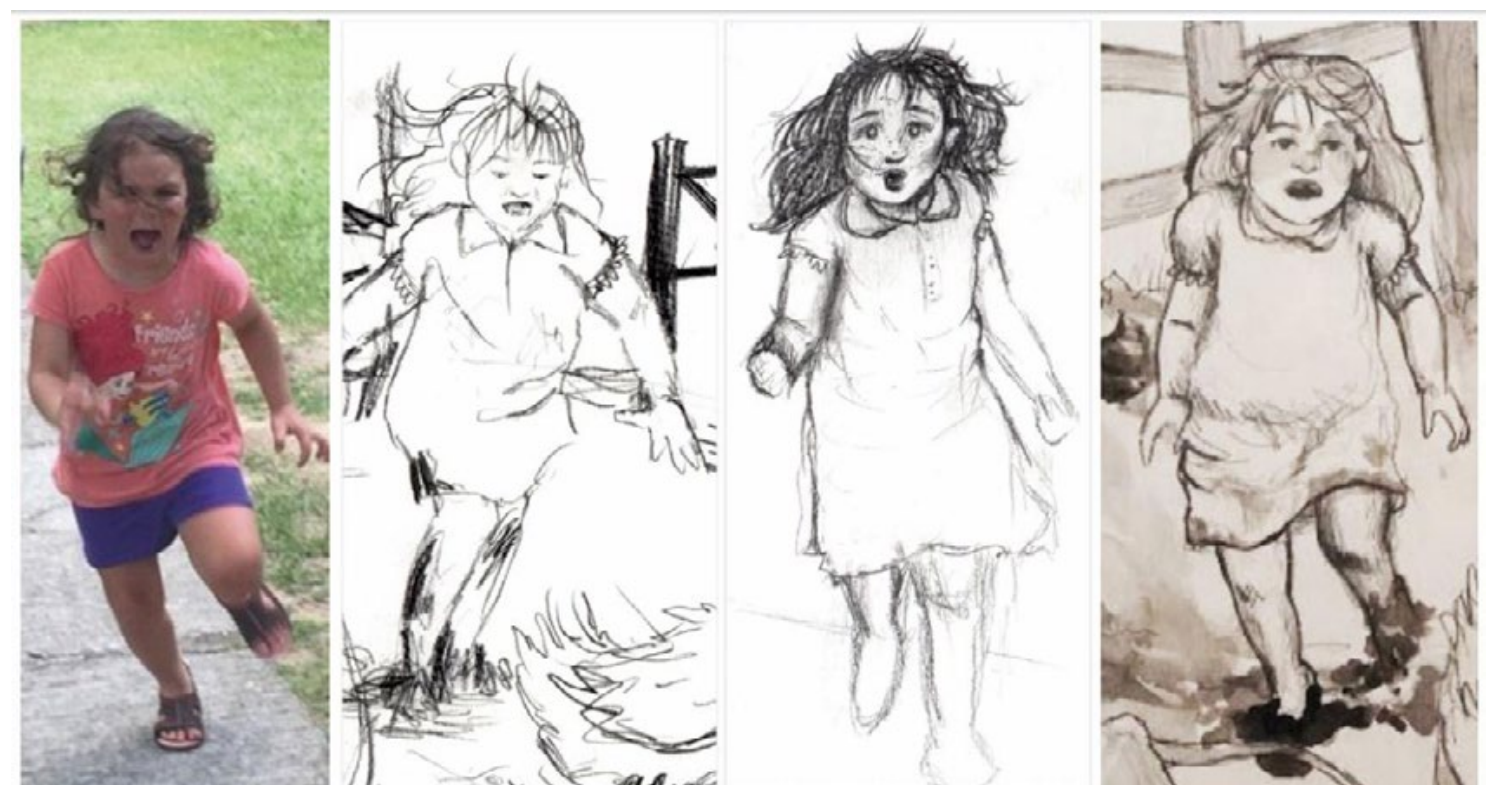

Fig. 1: Pacheco, Diagrama do desenvolvimento de uma ilustração, 2018. Montagem digital: fotografia e ilustrações (lápis grafite e aquarela sobre papel). 
A narrativa de A Galinha Branca é situada na propriedade onde as crianças cresceram, no interior do Rio Grande do Norte. Era uma fazenda simples, composta pela casa amarela onde viviam eles, um armazém, uma casa de farinha, o curral e os metros de roçado que se estendiam pelo quintal. Para a construção do cenário, foram utilizadas fotografias antigas e atuais do local, além de lembranças e relatos.

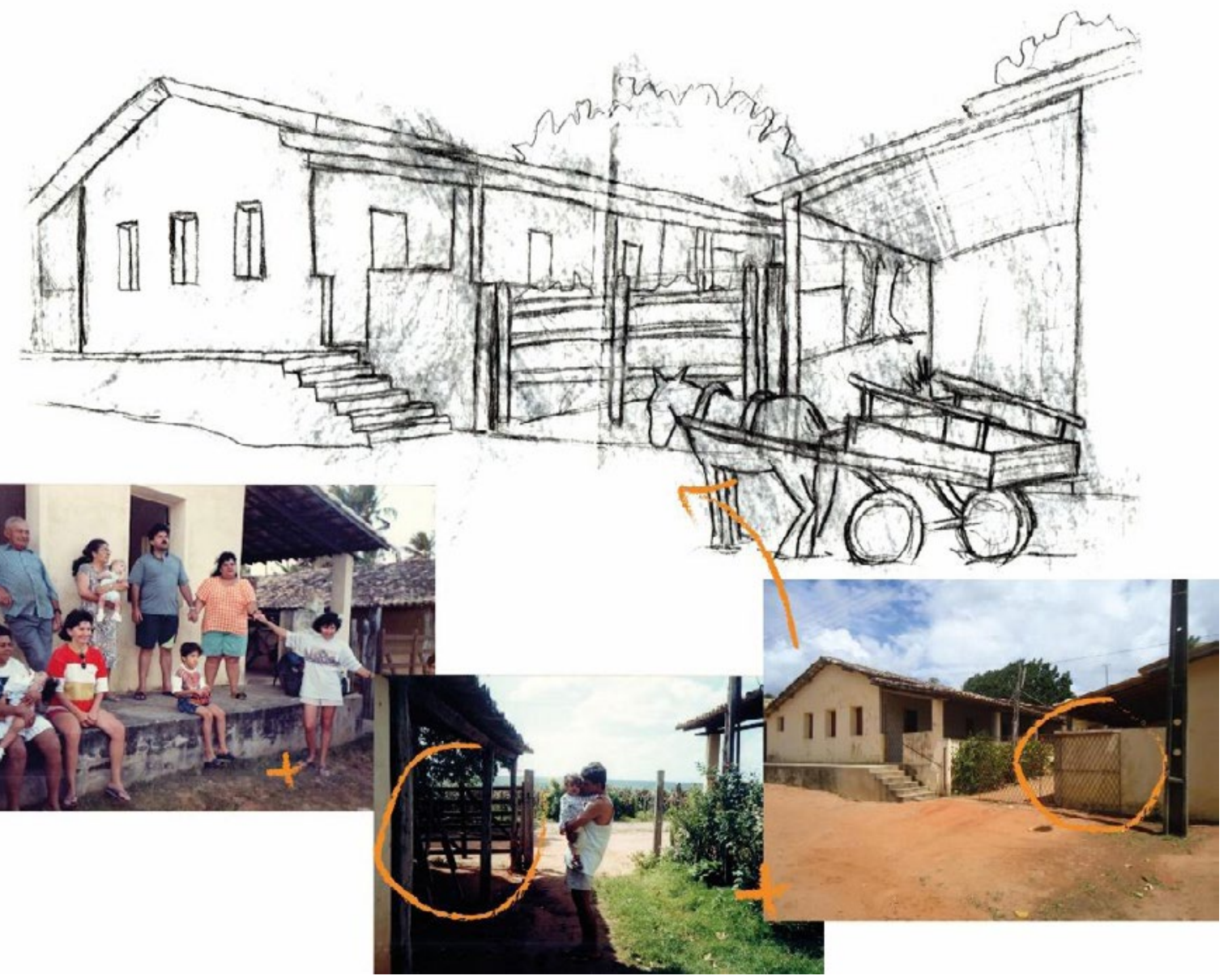

Fig. 2: Pacheco, Esquema da construção do cenário, 2018. Montagem digital contendo fotografias e o esboço de uma ilustração, realizado em lápis grafite. Fotos do acervo pessoal da autora.

Oliveira (2008) destaca a importância do cuidado com a organização do cenário na produção de uma ilustração, dizendo que a escolha do modo de ver a cena cria uma relação de proximidade com o leitor. O ponto de vista determina como o espectador é inserido e aumenta o poder de convencimento da imagem.

Os primeiros esboços, feitos com lápis grafite, foram desenhos rápidos, "sujos", cheios de manchas, traços sobrepostos e de marcações, com o único intuito de idealizar as composições. Alguns dos esboços surgiram sem precisar de imagens de referência, sendo baseados apenas em memórias. Por ter sido um processo simultâneo em que texto, ilustração e diagramação estão interligados, algumas ilustrações já foram pensadas para ocupar os espaços deixados pelo texto, outras foram feitas livremente, em seguida sendo adaptadas ao espaço, e ainda outras foram feitas para ocupar a maior parte ou toda a página, deixando espaços limitados para o texto ou 
trazendo-o para dentro do desenho. Foi o caso da parede de porta-retratos, que foi ilustrada na folha de guarda em páginas duplas, mostrando pessoas importantes e objetos que remetem à vida no interior, crenças etc.

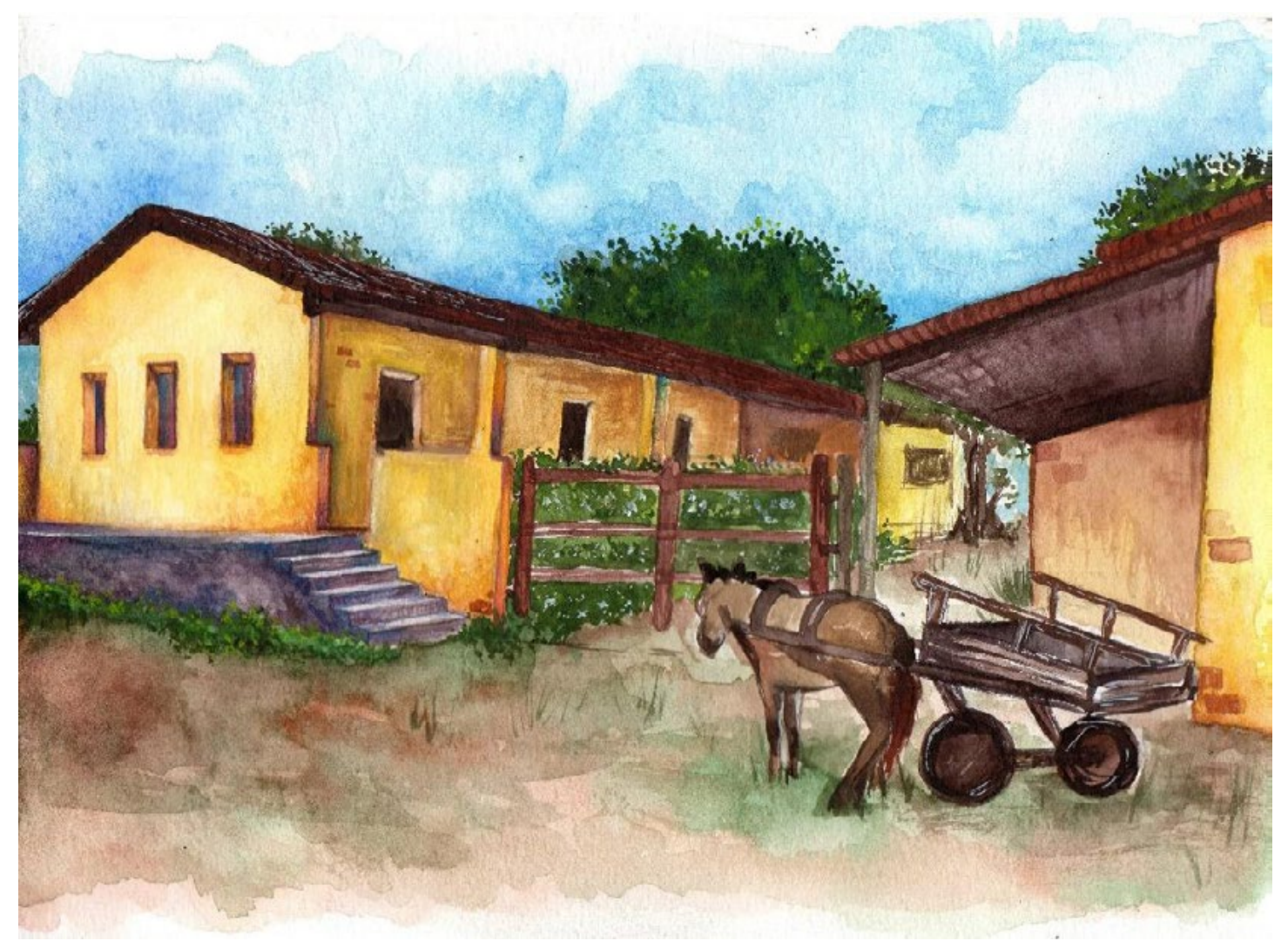

Fig. 3: Pacheco, A Casa Amarela, 2018. Ilustração, aquarela e lápis de cor sobre papel.
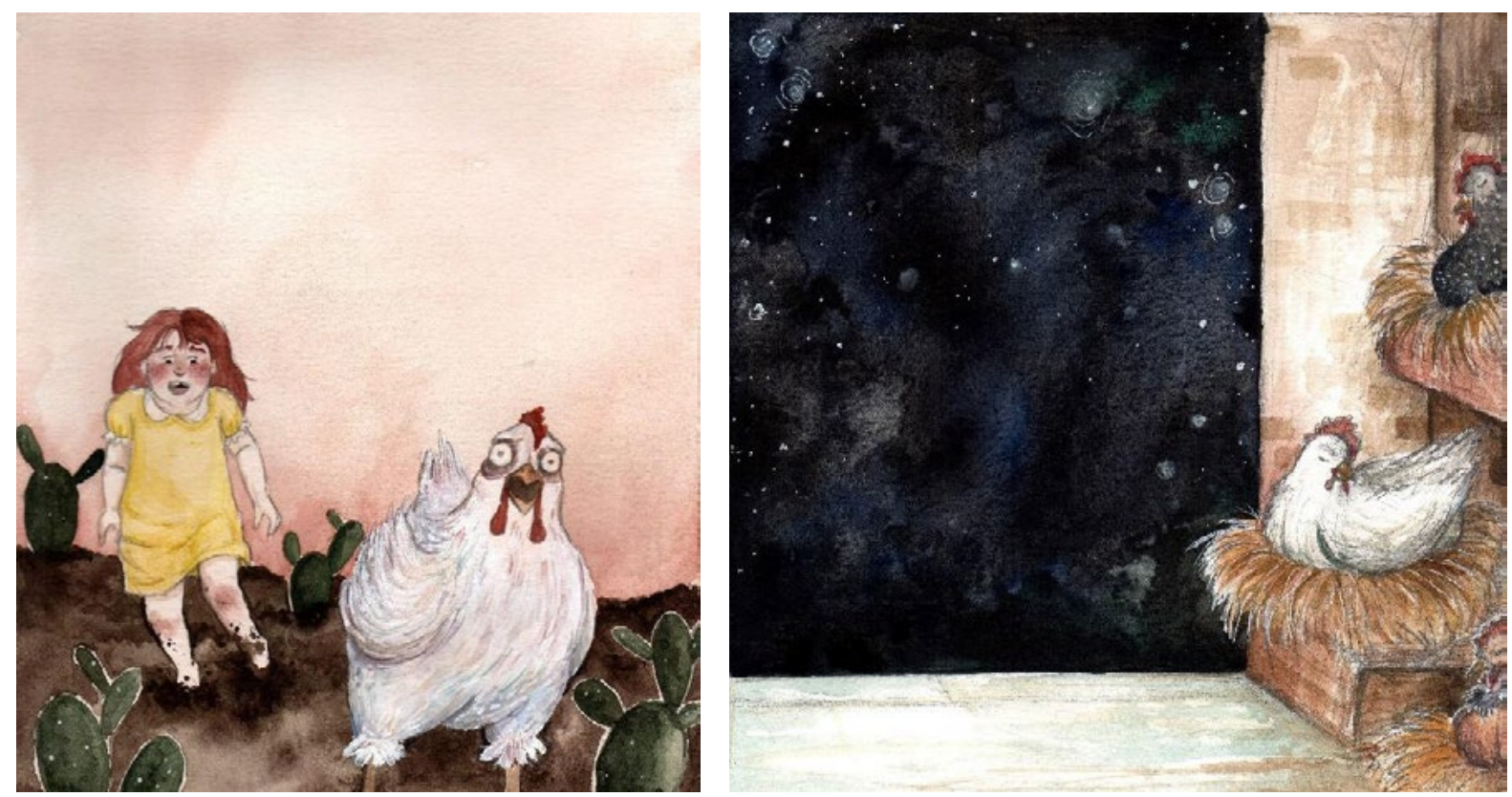

Fig. 4 e 5: Pacheco, Capa; É noite no galinheiro. 2018. Aquarela, guache, grafite e gel sobre papel. Ambas as ilustrações foram pensadas com espaço determinado para o texto. 
Ressalta-se aqui a importância das páginas duplas compostas somente pela ilustração. Nessas páginas a narrativa é contada unicamente pelas imagens, mostrando ao leitor o que estava acontecendo naquela cena, mas também o deixando com uma margem confortável para imaginar além do que está desenhado.

As ilustrações do livro foram planejadas para apresentar muitos detalhes, aproveitando a aparência dos materiais e do suporte onde foram colocados. Biazetto (2008) diz que a percepção de uma imagem depende de vários elementos visuais, que conduzem o olhar do leitor por ela, dentre eles estão superfície, volume, luz e cor. De acordo com Biazetto, a cor é o elemento visual com mais capacidade de seduzir o olhar e de provocar emoção no processo de percepção da imagem, uma vez que possibilita a criação de significados bastante diversos. Sendo assim, a escolha da paleta de cores é um passo importante e deve ser feita conscientemente.

Após ter terminado os rascunhos em grafite que completariam todo o livro, partiuse para a inserção das cores. Por se tratar de um cenário do sertão, a predominância foi de tons quentes, embora não se exclua tons mais frios, já que eles foram necessários para proporcionar contrastes e pontos de destaque.

As ilustrações foram pensadas para um suporte bidimensional bastante comum, que é o papel. A aquarela foi o material predominante utilizado, porém não o único, já que a associação de outros materiais poderia acrescentar qualidade expressiva ao trabalho e contribuir para o processo. Deve-se lembrar que não existe um único caminho para a criação de uma ilustração, que a técnica, os meios ou o estilo dessa produção são consequência das escolhas do artista/ilustrador, e que é possível explorar os limites dessas escolhas. Sendo assim, a mistura de mídias pretende contribuir para efeitos de contraste, volume e textura.

As autoras Nikolajeva e Scott (2011) definem livro ilustrado como o tipo de produção que suporta as linguagens verbal e não verbal de maneira igual, sendo ambos igualmente essenciais para a interpretação completa da obra. De acordo com essas autoras, a ilustração pode ter a função de contraponto, reforço ou redundância à narrativa textual. Ramos (2013) completa esse pensamento ao dizer que as imagens presentes em um livro ilustrado têm o potencial de concordar, tensionar, negar, expandir ou propor uma nova visualidade ao que está dito no texto escrito.

Van der Linden (2011) diz que várias produções da literatura ilustrada exibem sinais do instrumento utilizado pelo artista, como pincel, lâminas, dedos e outros, bem como, deixam visível a marca do gesto e os suportes originais, tais quais papel, papelão, tela, madeira. Essas marcas podem ser vistas como evidências do traço pessoal do artista, uma vez que é possível identificar técnicas, materiais e gestos do ilustrador como característicos da individualidade de seus trabalhos.

Em Pelos Jardins Boboli (2008), Oliveira afirma que os desenhos são como um alfabeto pessoal do artista, uma caligrafia própria e individual. Também destaca que um bom desenho e estruturação satisfatória não é pressuposto de que se vá obter boas ilustrações. A partir daí, Oliveira levanta o questionamento que é também compartilhado nesta pesquisa: o que seria desenhar bem para o ilustrador? Ele diz que o significado do bom desenho no universo da ilustração é aquele capaz de captar 
a sonoridade das palavras e a essência das cenas. Além disso, ele também destaca que parte da qualidade da ilustração se dá pela adequação visual ao texto.

Também se destaca a afirmação de Ramos (2013), quando ressalta que não é a quantidade de ilustrações que vai definir o valor e a importância de um livro, mas sim a função que estas exercem conjuntamente com a narrativa. Portanto, todos os detalhes são importantes quando se trata da arte de contar histórias com ilustrações.

A ilustração deve cativar a curiosidade, de maneira que possa incitar novas leituras complementares àquelas que estão visíveis. Uma concepção que sumariza bem essa relação é a que diz que a ilustração seria como um prisma, jamais como um espelho. Sendo assim, o ilustrador deve trabalhar nessa interseção entre o que se pode olhar e o que não se pode, por não estar visivelmente ilustrado. $\bigcirc$ resultado disso é o encantamento, a cristalização da imagem literária na memória do leitor.

Por fim, aqui considera-se pertinente a fala de Biazetto (2008), na qual ela diz que cada ilustração proposta para um livro deverá estar bem resolvida, não somente de maneira isolada em seus aspectos particulares, mas também em conjunto com as demais e com o texto. A partir dessa afirmação, abre-se espaço para falar a respeito da diagramação e do projeto gráfico, tópicos que serão discutidos adiante.

\section{Relação texto e imagem}

Van der Linden (2011) afirma que o livro ilustrado traz em si texto e imagem, e que a relação entre eles só se torna possível quando colocamos os dois de maneira equilibrada. Fittipaldi (2008) completa o pensamento dessa autora quando afirma que entre o texto e a imagem há uma relação de intimidade, de forma que quando interligados, o texto que conta a história e a imagem que a reconta por meio de outras interpretações, vão ressignificar as narrativas.

Moraes (2008) destaca que o livro é um objeto que tem corpo, e que esse corpo delimita forma, tamanho, cor, tato e cheiro. Esses elementos são os fatores que determinam como o objeto livro se apresenta para nós. Ele também afirma que o projeto gráfico é o procedimento pelo qual o livro vai propor seus espaços, relacionar seus textos e imagens e construir assim o ambiente que será percorrido pelo leitor, além de determinar como ele realizará esse trajeto.

Ramos (2013) reforça a importância da diagramação, ao apontar que por meio desse processo, se torna possível saber à primeira vista do que se trata o material que se tem em mãos. Além disso, ela diz que a escolha da tipografia vai tornar o texto mais ou menos legível, mais ou menos atrativo para leitura. A fala de Oliveira (2008) é complementar quando acrescenta que é primordial considerar os espaços vazios na diagramação, bem como as relações entre manchas de texto, a tipografia escolhida, as vinhetas e as imagens. Ambos os autores concordam no enfoque à importância do formato dado à massa visual do texto.

Assim como Moraes, Bianco-Levrin (2011) concorda que é fundamental o 
ilustrador fazer parte do projeto gráfico do próprio livro, uma vez que essa ligação entre as diferentes etapas da produção vai proporcionar uma integração mais eficaz entre texto e imagem. É imprescindível haver esse diálogo e harmonia entre as pessoas responsáveis pelas etapas da produção do livro, para que este seja um objeto capaz de estimular o sensorial e a contemplação estética no leitor.

Seguindo adiante, foi pensado a respeito das dimensões. Observando custos e possibilidades de impressões, optou-se pelo formato $20 \mathrm{~cm} \times 20 \mathrm{~cm}$. Tendo essas definições estabelecidas, foi esboçado à mão como seria o livro, para ter noção de como as dimensões ficariam fisicamente e para desenvolver alguns protótipos das ilustrações. Essa boneca foi composta de rascunhos em grafite, e ajudou a ter uma noção inicial de quantos quadros seriam necessários e da localização de alguns componentes. Após isso, no aplicativo Adobe InDesign, foram elaboradas composições mais completas de como ficaria o preenchimento de cada página.

A respeito da tipografia, foi considerado que os possíveis leitores estariam em fase de alfabetização. Portanto, as fontes escolhidas prezavam por uma boa visibilidade no corpo do texto. A quantidade de texto varia em cada página, mas no geral, os parágrafos são curtos. Há também variação na forma como texto e imagens estão dispostos: há composições nas quais a imagem predomina, ou nas quais a narrativa é contada apenas pelas imagens; em outras, o texto é mais evidente, e há ainda as que a ocupação do espaço ocorre de maneira mais igual.

Pensando no livro como objeto, coube considerar como seria a pegada do leitor nele. Tendo em vista que o livro A Galinha Branca foi pensado para crianças, devido ao tamanho das mãos, o espaço da pegada não precisa ser tão grande. Considerando as medidas escolhidas e o número de páginas, o livro pode ser manuseado de forma livre, sem maiores implicações causadas pelo peso do objeto.

Após terminados os esboços coloridos das ilustrações, foi feita uma terceira boneca, utilizando a mesma estrutura de diagramação do segundo protótipo, apenas adequando as imagens e fazendo os ajustes necessários, como correções no texto e adição de páginas. Foram impressas algumas páginas dessa boneca para visualizar como ficaria o material impresso em cores. Por fim, completou-se a diagramação no Adobe InDesign, utilizando as ilustrações finalizadas e preparando o material para a versão final. As impressões foram feitas em gráfica, sendo a capa feita de papel cartão e o miolo de papel couchê. Essa escolha prezou por melhor qualidade de cobertura da tinta, tamanho certo e material adequado e acessível.

\section{Processo criativo \& registro}

Inicialmente, destaca-se a definição de processo criativo em arte formulada por Salles (2006), a qual diz que o processo de criação pode ser explicado como um movimento dinâmico, flexível e de variação contínua, no qual não se consegue determinar um ponto inicial, nem final, que é sustentado pela lógica da incerteza, e que abre espaço para a intervenção do acaso e para a introdução de novas ideias. Isto é, o processo da construção de uma obra de arte pode ser visto como algo em 
constante mudança, sujeito a intervenções e acréscimos em todas as suas etapas.

Portanto, devido a esse estado constante de "acúmulo", é impossível prever qual será o resultado desse movimento, já que não há como precisar um ponto final ou inicial. Sugere-se então, pensar o processo como algo que não se sabe ao certo quais foram as motivações exatas ou em que ponto da vida do artista elas surgiram, bem como, não se sabe até que ponto esse caminho de construção pode ir, a menos que se experimente até onde a linha pode se esticar.

Iniciou-se o registro desse processo criativo em um caderno de artista, porém, o material de que ele era feito não era favorável ao uso de mídias que requerem absorção de água ou pigmento. Por causa disso, optou-se por não fazer os desenhos nesse caderno, que passou a ser utilizado para anotações, para colagens de referências e de rascunhos feitos em outras superfícies.

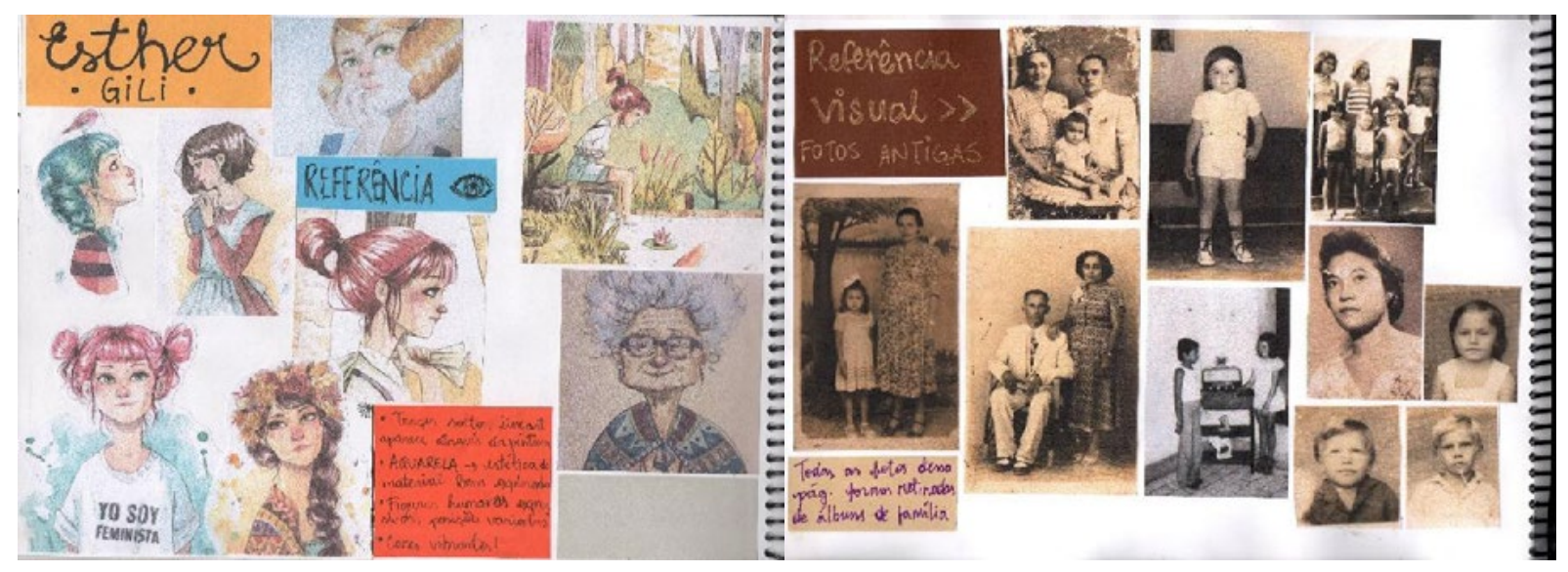

Fig. 6 e 7: Pacheco, Caderno de artista 1 e 2, 2018. Páginas retiradas do caderno de processos, contendo colagens de referências visuais.

Discutiu-se acerca da utilização de um fichário como suporte de registro. Embora fosse uma opção que apresentaria bastante flexibilidade, proporcionando ordenar, acrescentar ou retirar materiais de acordo com o que se julgasse pertinente para essa construção, havia a questão de que a possibilidade de alteração da sequência dos registros acabaria apagando o rastro do processo de criação.

De acordo com Salles (2013), o rastro é definido como os vestígios deixados pelo artista, que oferecem modos de captar como se desenvolveu o pensamento criativo, quais foram as ideias e as decisões tomadas naquele ponto da produção, qual foi o caminho percorrido até chegar ao resultado. O rastro permite a um observador externo perceber detalhes, novas perspectivas e até criar teorias a respeito do que não necessariamente estaria visível para aquele que apenas olhasse o produto do processo. Logo, optou-se por manter o caderno de artista com o qual tinha iniciado a documentação do processo, mas não foi descartado o uso do fichário para arquivar o conteúdo que não era comportado pelo caderno.

Retomando que no processo criativo não há como saber qual o ponto inicial nem o final, considera-se importante falar a respeito das referências que, como artistas, vamos recolhendo ao longo da vida de forma não intencional. Salles (2006) diz que o artista trabalha imerso em sua cultura e tradição, e que acontecimentos corriqueiros 
podem abrir inúmeras possibilidades de ideias, que podem ser desenvolvidas e refletidas em suas produções. Pode-se dizer que a arte produzida por esse artista se permeia com sua vida em diversos aspectos, estando ligada a tempos, espaços e fortes marcas pessoais. No caso de A Galinha Branca, um dos fatores motivadores de sua produção foi a ideia de transformar as histórias ouvidas na infância de uma das autoras em ilustrações. Ou seja, sem que se percebesse, esse processo começou bem antes do momento específico em que foi decidido.

Para atender a proposta de deixar o desenvolvimento do processo de criação evidente, procurou-se organizar o conteúdo na ordem em que foi acontecendo, e, para facilitar o entendimento do leitor, adotou-se a expressão ações de pesquisa para referir-se às ações que possibilitaram a realização deste trabalho. Essa expressão descreve as etapas do processo criativo sem exigir que elas tenham acontecido numa ordem específica, já que o processo não acontece de forma linear. Sendo assim, todo o processo foi dividido em cinco ações de pesquisa: consulta bibliográfica, construção da narrativa, concepção das ilustrações, relação texto x imagem e registro do processo criativo. O diagrama abaixo mostra como se deu a distribuição dessas ações no decorrer dos dois anos de desenvolvimento delas, sendo cada linha vertical a representação de um mês e os blocos coloridos as ações ao longo desse período. Cada ação de pesquisa está caracterizada por uma cor.

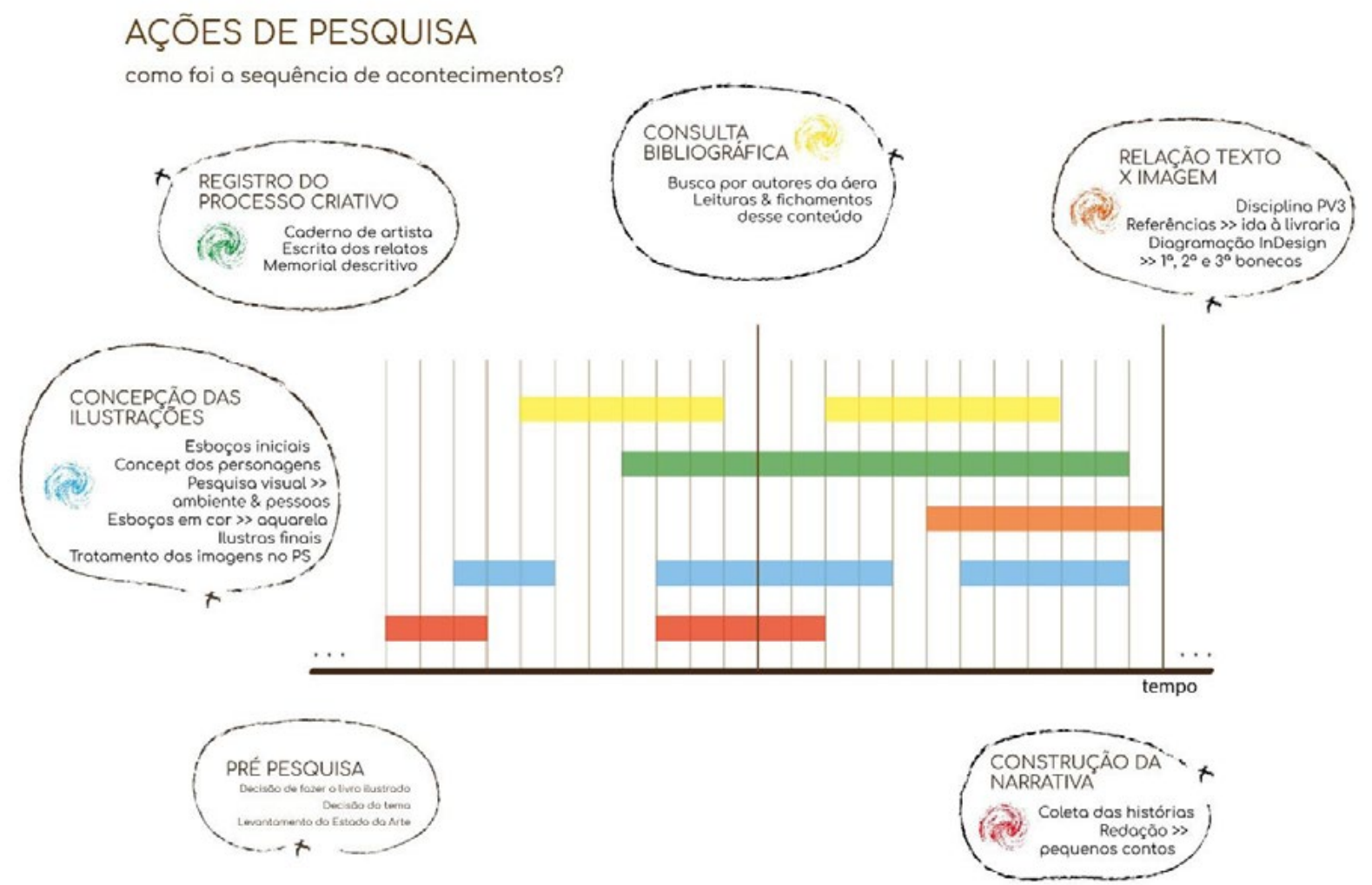

Fig. 8: Pacheco, Diagrama das Ações de Pesquisa, 2018.

Outro ponto importante que diz respeito a esta pesquisa é que a teoria surgiu como resposta à prática. As experiências reais que estavam sendo vivenciadas no processo fizeram necessário buscar conteúdos teóricos que pudessem embasar aquilo 
que estava sendo feito e responder aos questionamentos que haviam surgido. Salles (2013) diz que o artista levanta hipóteses e vai testando-as continuamente.

Pensando no âmbito da aplicação didática do trabalho, considerou-se que, além de destacar o processo e suas etapas no caderno de artista, seria pertinente também mostrar partes do desenvolvimento das ilustrações na estrutura do próprio livro ilustrado. O propósito foi mostrar diferentes fases de finalização das ilustrações que compõem A Galinha Branca, de forma que a criança pudesse perceber que existe um processo atrás daquela imagem, que ela não surgiu pronta daquela forma.

Fig. 9 e 10: Pacheco, Tuca pega a galinha 1 e 2, 2018. Ilustrações (grafite e aquarela sobre papel).
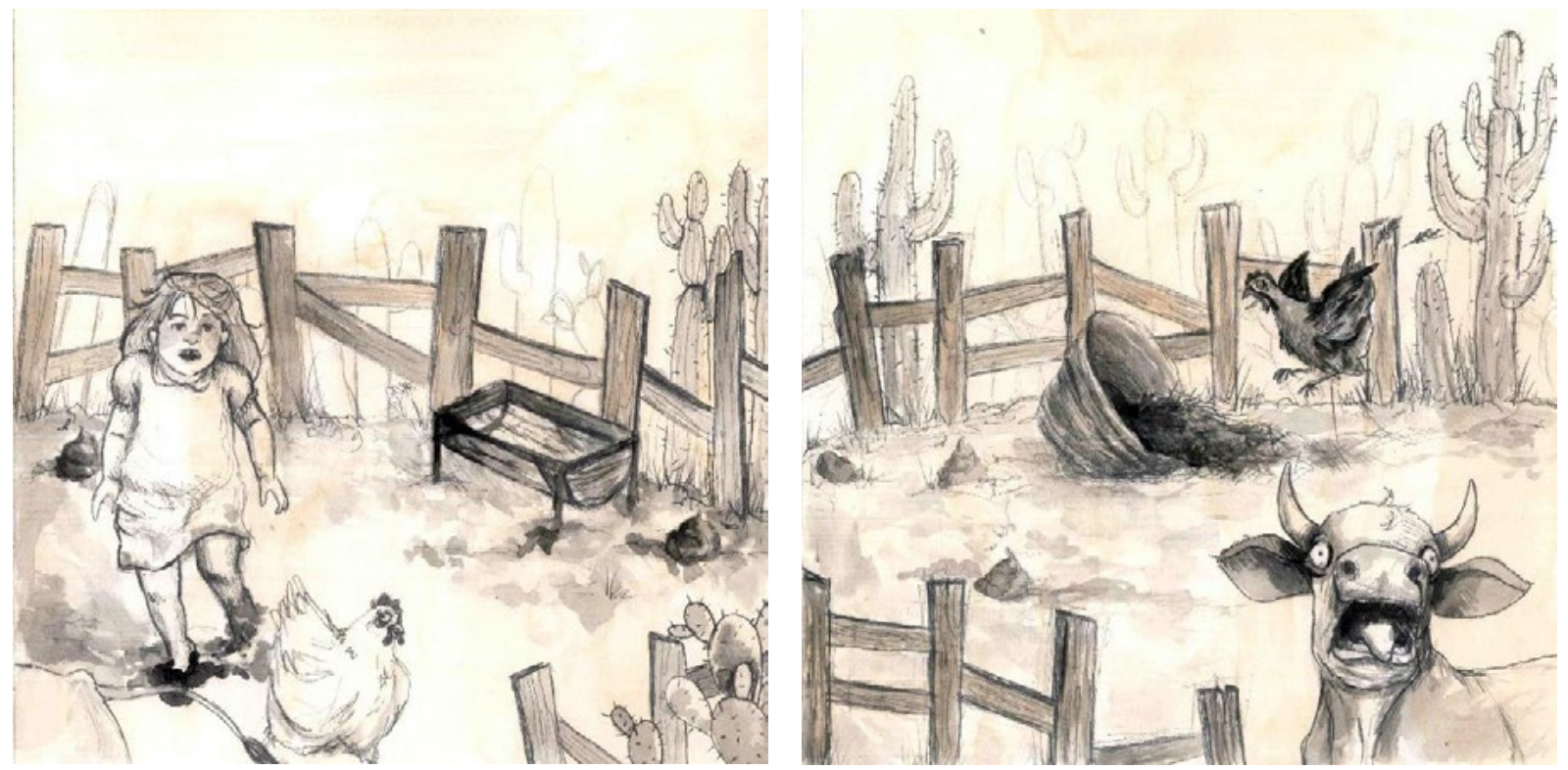

\section{Considerações finais}

Neste artigo, buscou-se responder à questão do que seria necessário para a criação de livros ilustrados, considerando os aspectos relacionados à narrativa, às ilustrações e à diagramação. Além disso, foi abordada a produção do livro ilustrado $A$ Galinha Branca, falando de suas etapas e pensando acerca de seu processo criativo. Ao final dessa trajetória, é possível elencar algumas reflexões conclusivas.

Primeiramente, no âmbito da narrativa e da literatura para a infância, foi questionado como se deveria escrever histórias para crianças: o que levar em consideração? Como definir o que seria próprio ou não? Como foi discutido e embasado pela fala das autoras Meireles, Zilberman e Cademartori, um dos principais quesitos a se considerar é que, quem diz o que é ou não relevante para leitura do público infantil é a própria criança. Apesar de não haver uma fórmula padrão, o fator da identificação com o que é contado tem grande significância. Brenman sugere se colocar no lugar da criança e tentar relembrar a própria infância, retomar o que nos chamava a atenção e nos instigava. Assim, para a produção de A Galinha Branca, as histórias não foram filtradas para servirem de exemplo, possibilitando às crianças se 
identificarem com os personagens e suas aventuras.

Posteriormente, foi trazido à tona a questão da produção das ilustrações, novamente levantando a pergunta: o que é necessário à ilustração? Qual o seu lugar e peso no livro ilustrado? É de concordância dos autores citados que, a ilustração não deve tentar superar o texto, assim como o texto também não deve se sobressair à ilustração. A imagem não vai ser redundante ao texto, pelo contrário, vai proporcionar uma visão expandida daquilo que está escrito. A ilustração só desperta interesse se deixar uma margem para a imaginação. O papel da ilustração no livro seria proporcionar que o leitor crie imagens pessoais, que estariam escondidas dentro do livro que se está lendo, apenas visíveis ou imagináveis para cada um. Pensando nisso, em algumas páginas a narrativa foi composta só por imagens, possibilitando uma leitura mais livre do que estava sendo representado, em outras, onde o texto era predominante, foram inseridas ilustrações de objetos ou ícones que tivessem relação com a história, de forma que instigassem a imaginação.

Em seguida, foi discutida a relação entre texto e imagem pictórica no contexto do livro ilustrado. Van der Linden (2011) afirma que essa relação só é possível quando ambas as partes são colocadas de forma que uma contribua com a outra.

Outro ponto abordado foi a diagramação, processo pelo qual o livro propõe como relacionar textos e imagens e construir o caminho que o leitor vai percorrer. É a diagramação que vai dar a cara do livro, por isso, cada detalhe é importante. Ainda nesse âmbito, Moraes (2008) enfatiza que é fundamental o ilustrador fazer parte do projeto gráfico do livro, uma vez que essa ligação entre as diferentes etapas da produção vai proporcionar uma integração mais eficaz entre texto e imagem.

Por fim, falou-se quanto ao processo criativo e de seu registro. Salles (2006 e 2013), autora utilizada para embasar essa discussão, afirma que no processo de criação artística não há como determinar ponto inicial nem final, bem como, não se pode prever quais serão os resultados. Construir uma obra de arte é um processo de constante mudança. Ao pensar nas formas de registro dessa construção, o rastro do processo é outro ponto relevante. Salles o define como traços deixados pelo artista, que oferecem maneiras de captar como se deu o pensamento criativo.

\section{Referências}

BIANCO-LEVRIN, Nicolas. As sequências de imagens. In: VAN DER LINDEN, Sophie. Para Ler o Livro Ilustrado. São Paulo: Cosac Naify, 2011.

BIAZETTO, Cristina. As cores na ilustração do livro infantil e juvenil. In: OLIVEIRA, leda de (Org.) O que é qualidade em ilustração no livro infantil e juvenil: com a palavra o ilustrador. São Paulo: DCL, 2008.

BRENMAN, Ilan. Mostrar ou não mostrar? Eis a questão. Coluna Palavrórios e Rabugices. Edição 229. Revista Crescer. Porto Alegre: Editora Globo, 2012. < https://revistacrescer. 
globo.com/Colunistas/llan-Brenman/noticia/2013/03/mostrar-ou- -nao-mostrar-eis-questao. html > acesso em 02 Nov. 2018.

CADEMARTORI, Lígia. O que é literatura infantil. $7^{\text {a }}$ ed. São Paulo: Editora Brasiliense, 2006.

DIAS, Belidson. A/r/tografia como metodologia e pedagogia em artes: uma introdução. In: DIAS, Belidson; IRWIN, Rita L. (Org.). Pesquisa Educacional Baseada em Arte: A/r/tografia. $1^{\text {a }}$ ed. Santa Maria: Editora UFSM, 2013.

FITTIPALDI, Ciça. O que é uma imagem narrativa? In: OLIVEIRA, leda de (Org.) O que é qualidade em ilustração no livro infantil e juvenil: com a palavra o ilustrador. São Paulo: DCL, 2008.

MEIRELES, Cecília. Problemas da literatura infantil. Rio de Janeiro: Nova Fronteira, 2016.

MORAES, Odilon. O projeto gráfico do livro infantil e juvenil. In: OLIVEIRA, leda de (Org.) O que é qualidade em ilustração no livro infantil e juvenil: com a palavra o ilustrador. São Paulo: DCL, 2008.

NIKOLAJEVA, Maria; SCOTT, Carole. Livro ilustrado: palavras e imagens. São Paulo: Cosac Naify, 2011.

OLIVEIRA, leda de (Org.) O que é qualidade em ilustração no livro infantil e juvenil: com a palavra o ilustrador. São Paulo: DCL, 2008.

OLIVEIRA, Rui de. Pelos Jardins Boboli: reflexões sobre a arte de ilustrar livros para crianças e jovens. Rio de Janeiro: Nova Fronteira, 2008.

RAMOS, Graça. A imagem nos livros infantis: caminhos para ler o texto visual. $2^{\mathrm{a}}$ ed. Belo Horizonte: Autêntica Editora, 2013.

SALLES, Cecília Almeida. Gesto inacabado: processo de criação artística. $6^{a}$ ed. São Paulo: Intermeios, 2013.

SALLES, Cecília Almeida. Redes da criação: construção da obra de arte. $2^{a}$ ed. São Paulo: Editora Horizonte, 2006.

VAN DER LINDEN, Sophie. Para ler o livro ilustrado. São Paulo: Cosac Naify, 2011.

ZAMBONI, Silvio. A pesquisa em arte: um paralelo entre arte e ciência. $4^{\text {a }}$ ed. Campinas, SP: Autores Associados, 2012.

ZILBERMAN, Regina. A produção cultural para a criança: a criança e a produção cultural. $4^{a}$ ed. Porto Alegre: Mercado Aberto, 1990.

Recebido em 20 de julho de 2020.

Aprovado em 10 de agosto de 2020. 